\title{
Effect of exercise training on ventilatory efficiency in patients with heart disease: a review
}

\author{
D.M.L. Prado ${ }^{1}$, E.A. Rocco ${ }^{1}$, A.G. Silva ${ }^{1,2}$, D.F. Rocco ${ }^{2}$, M.T. Pacheco ${ }^{2}$ and V. Furlan ${ }^{1}$ \\ ${ }^{1}$ Grupo TotalCare-Amil, São Paulo, SP, Brasil \\ ${ }^{2}$ Universidade Santa Cecília, Santos, SP, Brasil
}

\begin{abstract}
The analysis of ventilatory efficiency in cardiopulmonary exercise testing has proven useful for assessing the presence and severity of cardiorespiratory diseases. During exercise, efficient pulmonary gas exchange is characterized by uniform matching of lung ventilation with perfusion. By contrast, mismatching is marked by inefficient pulmonary gas exchange, requiring increased ventilation for a given $\mathrm{CO}_{2}$ production. The etiology of increased and inefficient ventilatory response to exercise in heart disease is multifactorial, involving both peripheral and central mechanisms. Exercise training has been recommended as non-pharmacological treatment for patients with different chronic cardiopulmonary diseases. In this respect, previous studies have reported improvements in ventilatory efficiency after aerobic exercise training in patients with heart disease. Against this background, the primary objective of the present review was to discuss the pathophysiological mechanisms involved in abnormal ventilatory response to exercise, with an emphasis on both patients with heart failure syndrome and coronary artery disease. Secondly, special focus was dedicated to the role of aerobic exercise training in improving indices of ventilatory efficiency among these patients, as well as to the underlying mechanisms involved.
\end{abstract}

Key words: Heart disease; Ventilatory efficiency; Exercise test; Exercise training

\section{Introduction}

Cardiopulmonary exercise testing (CPX) has proven useful for quantifying aerobic capacity and is, therefore, valuable for identifying exercise tolerance in patients with cardiac disease (1-3). Furthermore, CPX responses re flecting ventilatory inefficiency during exercise have at tracted a great deal of interest (3-5). Notably, previous investigations (6-9) have shown that patients with heart disease exhibit ventilatory inefficiency, suggesting the existence of mixed impairment of multiple organ systems. In this context, the etiology of increased and inefficient ventilatory response to exercise in cardiac disease is multifactorial, involving both peripheral (e.g., locomotor muscle afferents and oxidative metabolism) and central (e.g., ventilation/ perfusion mismatch) mechanisms $(6,8,9)$.

Importantly, aerobic exercise training has been recommended as non-pharmacological treatment for patients with a variety of different comorbidities (10-12). In this respect, a growing body of research $(6,7,13,14)$ has documented increased aerobic fitness in patients with cardiac disease after aerobic exercise training. In addition, previous studies $(6,7,14)$ have demonstrated improvements in ventilatory efficiency after exercise training programs. The primary purpose of this brief review was to elucidate the pathophysiological mechanisms underlying abnormal ventilatory response to exercise, with special emphasis on patients with heart failure syndrome and coronary artery disease. Secondly, special focus was dedicated to the role of aerobic exercise training in improving the indices of ventilatory efficiency among these patients, as well as to the underlying mechanisms involved. More specifically, these indices include ventilation to carbon dioxide production relationship $\left(\mathrm{VE} / \mathrm{NCO}_{2}\right)$ and end-tidal $\mathrm{CO}_{2}$ pressure $\left(\mathrm{P}_{\mathrm{ET}} \mathrm{CO}_{2}\right)$.

\section{Determinants of exercise ventilatory response}

Exercise hyperpnea is considered to be one of the major remaining challenges to understanding the integrated multi-system responses to exertion. During physical exercise, there is an increase in metabolic rate and consequently in ventilatory demands. Three physical factors determine the ventilatory response to exercise (15): 1) metabolic $\mathrm{CO}_{2}$ production; 2) mean arterial $\mathrm{CO}_{2}$ tension $\left(\mathrm{PaCO}_{2}\right)$ or set point, and 3$)$ the physiological dead space to tidal volume ratio (VD/VT). Mathematically, ventilatory response during exercise may be explained

Correspondence: D.M.L. Prado: <danilomprado@.usp.br> 
using the modified alveolar equation (15): $\mathrm{VE}=863 \times$ $\mathrm{VCO}_{2} \mathrm{PaCO}_{2}$ [(1-VD/VT)], where: 863 is the constant correcting for the different standard conditions used to report ventilatory and gas exchange volumes, i.e. body temperature pressure and saturation (BTPS) and standard temperature and pressure dry (STPD), respectively; $\mathrm{VCO}_{2}$ : pulmonary $\mathrm{CO}_{2}$ output; $\mathrm{PaCO}_{2}$ : arterial $\mathrm{PaCO}_{2}$; VD/VT: physiological dead space to tidal volume.

In healthy subjects, the dynamics of ventilatory response to aerobic exercise are closely coupled to pulmonary $\mathrm{VCO}_{2}$. In this context, adequate increases in alveolar ventilation requirements are primordial to wash out metabolic $\mathrm{CO}_{2}$. In contrast, the rate of pulmonary $\mathrm{CO}_{2}$ exchange is further increased at the exercise intensity associated with metabolic acidosis. In other words, additional $\mathrm{CO}_{2}$ is produced by the anion bicarbonate $\left(\mathrm{HCO}_{3}{ }^{-}\right)$component of proton $\left(\mathrm{H}^{+}\right)$buffering at these work rates. This results in a more rapid rate of change in $\mathrm{VCO}_{2}$ relative to oxygen consumption $\left(\mathrm{VO}_{2}\right)$ during incremental exercise tests. It is important to recognize that the extra $\mathrm{CO}_{2}$ produced under these conditions is a function of the amount of $\mathrm{HCO}_{3}{ }^{-}$decrease in the muscle and blood compartments (15). For instance, the excess $\mathrm{CO}_{2}$ released at the mouth during ramp exercise exceeding the ventilatory anaerobic threshold (VAT) is thought to derive from the pool of bicarbonate readily available in the blood and in well perfused tissues including the working muscles, with $0.4 \mathrm{~L}$ of $\mathrm{CO}_{2}$ released for every $1 \mathrm{mmol} / \mathrm{L}$ reduction in plasma bicarbonate concentration (16).

$\mathrm{PaCO}_{2}$ is normally regulated by respiratory chemoreception (central or peripheral) displaying a bidirectional pattern in which it is increased or remains unchanged during steady-state exercise (17). It has been suggested that peripheral chemoreceptors increase their sensitivity upon exercise; and that respiratory centers change their 'set-point' in response to oscillations in remaining $\mathrm{PaCO}_{2}$ or $\mathrm{H}^{+}$which are phasic with breathing and increase with exercise (17). In this respect, at exercise levels that induce metabolic acidosis (e.g., above VAT), compensatory hyperventilation occurs, lowering the $\mathrm{PaCO}_{2}$ required to constrain the fall in arterial $\mathrm{pH}$ (15).

Finally, VD/VT ratio reflects pulmonary gas exchange efficiency during exercise. In normal individuals, VD/VT falls from about $0.30-0.40$ units at rest to approximately 0.10-0.30 units at peak exercise $(18,19)$. Importantly, although volume of dead space (VD) increases during exercise because of the end inspiratory expansion of conducting airways, the VD increase is small compared to the increase in total tidal volume (VT) and therefore VD/NT decreases (15). Thus, the ventilation needed to wash out a liter of $\mathrm{CO}_{2}$ produced during exercise is proportionally reduced (i.e., enhanced gas exchange efficiency).

It is also important to point out the contribution of neural mechanisms of the exercise hyperpnoea to dynamic muscular exercise in humans. In this context, after exercise onset, there is an initial short period in which ventilation increases, despite any changes in both arterial blood gases and acid-base balance (15). More specifically, both central neural feedforward (i.e., descending locomotor command from the motor cortex may directly influence respiratory centers) and peripheral feedback from exercising muscles have been proposed as mediators $(15,20)$. In this sense, Fink et al. (20) demonstrated motor cortical involvement in the control of breathing during exercise in male subjects, through positron emission tomography. In respect to peripheral feedback, group III and IV afferent neurons innervating contracting locomotor muscle are related to increase ventilatory response during rhythmic exercise in humans $(21,22)$. For instance, with the onset of exercise, contraction induced mechanical and chemical stimuli begin to activate receptors on the terminal end of both thinly myelinated (group III, mechanoreflex) and unmyelinated (group IV, metaboreflex) nerve fibers located within skeletal muscle. This activation increases the discharge of these thin afferent muscle fibers, which project via the dorsal horn of the spinal cord to the nucleus of the solitary tract and the medullary cardiorespiratory controller neurons. In fact, the stimulation of limb locomotor groups III-IV afferent fibers (ergoreflex activation) clearly has the capability to increase ventilatory response to rhythmic exercise $(21,22)$. For instance, when group III/IV afferent muscle fibers from the lower limbs are pharmacologically blocked with intrathecal fentanyl during rhythmic leg exercise, circulation and pulmonary ventilation are substantially compromised (23). In this sense, significant hypoventilation is observed in the steady state exercise with pharmacologically blocked afferent muscle fibers (+3 to $8 \mathrm{mmHg}$ mean increase in $\mathrm{P}_{\mathrm{ET}} \mathrm{CO}_{2}$ ) (21).

\section{Measurement of ventilatory efficiency during exercise}

The analysis of ventilatory efficiency during CPX has proven useful for assessing the presence and severity of both heart $(9,24-26)$ and lung $(27,28)$ diseases. During exercise, efficient pulmonary gas exchange is characterized by uniform matching of lung ventilation with perfusion. By contrast, mismatching is marked by inefficient pulmonary gas exchange, requiring increased ventilation for a given $\mathrm{CO}_{2}$ production. Interestingly, from a mathematical standpoint $\mathrm{VE} / \mathrm{VCO}_{2}$ can be described as: $\left\{\mathrm{VE} / \mathrm{VCO}_{2}=\right.$ $\left.\mathrm{k} /\left[\left(\mathrm{PaCO}_{2}\right) \times(1-\mathrm{VD} / \mathrm{VT})\right]\right\}$.

This implies that factors related to low $\mathrm{PaCO}_{2}$ set point and abnormally high dead space fraction (elevated VD/ VT) associated with uneven ventilation-perfusion contribute to an excessive ventilatory response to exertion.

Currently, several different methods are used to assess ventilatory efficiency during exercise, such as $\mathrm{VE} / \mathrm{VCO}_{2}$ relationship and $\mathrm{P}_{\mathrm{ET}} \mathrm{CO}_{2}$. With regard to $\mathrm{VE} /$ $\mathrm{VCO}_{2}$, there are a number of alternatives to express the $\mathrm{VE} / \mathrm{VCO}_{2}$ relationship during exercise (29-31), such as: 1) slope of $\mathrm{VE}$ versus $\mathrm{VCO}_{2}$ from beginning of exercise to 
respiratory compensation point $\left(\mathrm{VE} / \mathrm{VCO}_{2}\right.$ rest-RCP) or up to peak exercise $\left(\mathrm{VE} / \mathrm{VCO}_{2}\right.$ rest-Peak); 2) $\mathrm{VE} / \mathrm{VCO}_{2}$ ratio measured at VAT (VE/VCO 2 @VAT); 3) VE/VCO $\mathrm{CO}_{2}$ determined by averaging the three lowest consecutive 0.5-min data points (lowest $\mathrm{VE} / \mathrm{VCO}_{2}$ ), and 4) $\mathrm{VE} / \mathrm{VCO}_{2}$ ratio, measured during submaximal constant workload exercise.

It is important to emphasize that $\mathrm{VE} / \mathrm{VCO}_{2}$ ratio progressively increase with age and tend to be slightly lower in men than in women (31). In addition, the highest $\mathrm{VE} / \mathrm{VCO}_{2}$ slope values (e.g., $>34$ units) contribute to excess ventilation during exercise observed in patients with heart disease. Furthermore, it is not unusual to encounter values $>45$ in patients with severe heart failure or pulmonary hypertension $(5,32)$.

End-tidal $\mathrm{PCO}_{2}$ is defined as the highest partial pressure of $\mathrm{CO}_{2}$ at the end of expiration during tidal breathing. $\mathrm{P}_{\mathrm{ET}} \mathrm{CO}_{2}$ is used as a noninvasive index that is considered a good indicator for evaluating the ventilation/ perfusion relationship in patients over a wide range of conditions (33-35). In healthy individuals the normal pattern of $\mathrm{P}_{\mathrm{ET}} \mathrm{CO}_{2}$ response during graded exercise test is a progressive increase by approximately $5-8 \mathrm{mmHg}$ above resting values at VAT. Thereafter, $\mathrm{P}_{\mathrm{ET}} \mathrm{CO}_{2}$ becomes relatively constant or increases slightly until the onset of the respiratory compensation point during the isocapnic buffering period, and finally decreases progressively until the point of fatigue (Figure 1). The physiological determinants of $\mathrm{P}_{E T} \mathrm{CO}_{2}$ are: 1) metabolic rate (e.g., the rate of increase in mixed venous $\left.\mathrm{PCO}_{2}\right) ; 2$ ) breathing pattern (e.g., deepness of the previous inspiration (VT) and duration of the exhalation (expiratory time), and 3) increase in cardiac output and pulmonary blood flow, leading in better perfusion of the alveoli and reduced dead space (18).

With respect to $\mathrm{P}_{\mathrm{ET}} \mathrm{CO}_{2}$ analysis during exercise, the following methodologies are used: 1) change in $\mathrm{P}_{\mathrm{ET}} \mathrm{CO}_{2}$ from rest to VAT ( $\Delta \mathrm{P}_{\mathrm{ET}} \mathrm{CO}_{2}$ rest-VAT); 2) $\mathrm{P}_{\mathrm{ET}} \mathrm{CO}_{2}$ measured at VAT, highest value and peak of exercise, and 3) $\mathrm{P}_{E T} \mathrm{CO}_{2}$ measured during submaximal constant workload exercise $(30,33,36)$.

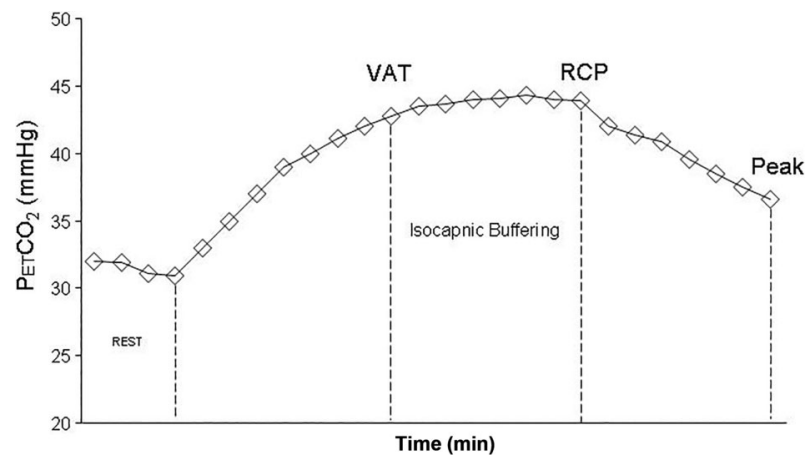

Figure 1. End-tidal $\mathrm{CO}_{2}$ pressure $\left(\mathrm{P}_{\mathrm{ET}} \mathrm{CO}_{2}\right)$ response during incremental exercise test in a healthy subject. VAT: ventilatory anaerobic threshold; RCP: respiratory compensation point.
For instance, a progressive decrease or lower increase in $\mathrm{P}_{\mathrm{ET}} \mathrm{CO}_{2}$ seems to be associated with blunted cardiac output response to exercise in cardiovascular disease $(35,36)$ (Figure 2). In addition, it is important to point out that Guazzi et al. (33) proposed a classification of ventilatory inefficiency based on four classes using both $\mathrm{VE} / \mathrm{VCO}_{2}$ slope and $\mathrm{P}_{\mathrm{ET}} \mathrm{CO}_{2}$ parameters (Figure 3).

\section{Ventilatory inefficiency in heart disease}

There is a growing body of evidence indicating impaired ventilatory efficiency in heart disease $(6-9,30,37)$. In this context, a previous study (37) has shown lower ventilatory efficiency in chronic heart failure (CHF) patients when compared to healthy peers $\left(\mathrm{VE} / \mathrm{VCO}_{2}\right.$ slope restpeak $=38.9 \pm 8.7$ vs $28.6 \pm 3.9$ units, respectively). In the same context, Woods et al. (8) performed a submaximal exercise test $\left(65 \%\right.$ of peak $\left.\mathrm{VO}_{2}\right)$ on a cycloergometer in patients with moderate-severe heart failure and in healthy controls. The authors observed greater $\mathrm{VE} / \mathrm{VCO}_{2}$ ratio values during submaximal exercise (45 \pm 9 vs $30 \pm 4$ units, respectively) and lower $\mathrm{P}_{\mathrm{ET}} \mathrm{CO}_{2}$ values $(29 \pm 6$ vs $40 \pm 3 \mathrm{mmHg}$, respectively) in patients compared to controls (8).

Notably, substantial evidence $(4,5,38-40)$ demonstrated that ventilatory inefficiency is an independent powerful prognostic marker for cardiac mortality or hospitalization in heart failure patients. A study conducted by Ponikowski et al. (40) with a 49-month follow-up showed that patients with normal peak $\mathrm{VO}_{2}\left(\geqslant 18 \mathrm{~mL} \cdot \mathrm{min}^{-1} \cdot \mathrm{kg}^{-1}\right)$ and $\mathrm{VE} / \mathrm{VCO}_{2}$ slope $\geqslant 34$ had a significantly higher mortality rate than patients with normal peak $\mathrm{VO}_{2}$ and $\mathrm{VE} / \mathrm{VCO}_{2}$ slope $<34$. This investigation was the first to introduce the concept that ventilatory inefficiency during exercise predicts mortality in patients with $\mathrm{CHF}$ even when having normal aerobic capacity (40).

Concerning patients with coronary artery disease (CAD), previous investigations have demonstrated lower ventilatory efficiency during exercise, albeit less marked than moderate-severe heart failure patients. In this respect, Eto et al. (41) observed abnormal $\mathrm{P}_{\mathrm{ET}} \mathrm{CO}_{2}$ response during exercise in CAD patients. Likewise, Rocco et al. (6) found higher values of VE/VCO 2 @VAT in $C A D$ patients with reduced aerobic capacity.

\section{Pathophysiological mechanisms involved in ventilatory inefficiency in heart disease}

As outlined previously, inefficient ventilatory response to exercise in heart disease is multifactorial, involving both peripheral (e.g., locomotor afferent muscle fibers and oxidative metabolism) and central (e.g., ventilation/perfusion mismatch) mechanisms. With regard to heart failure syndrome, mechanisms reported for increased ventilatory inefficiency during exercise include: 1) ventilation-perfusion mismatch; 2) early occurrence of metabolic acidosis, and 

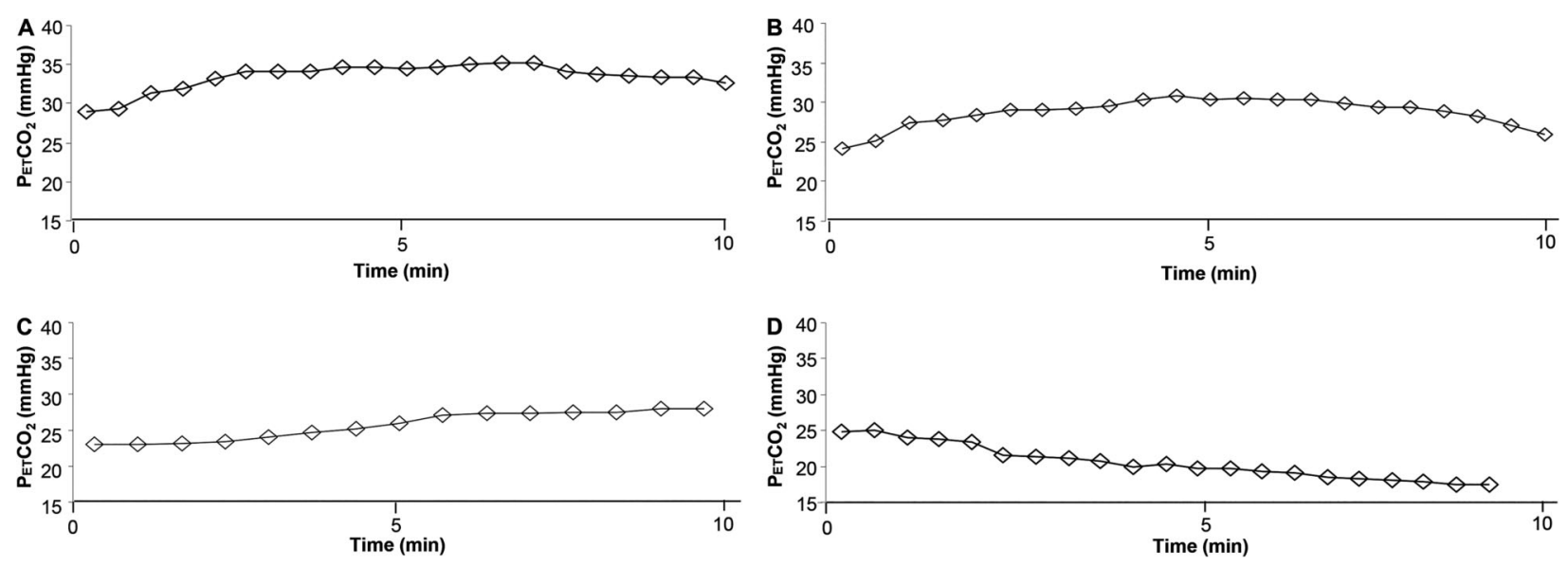

Figure 2. End-tidal $\mathrm{CO}_{2}$ pressure $\left(\mathrm{P}_{\mathrm{ET}} \mathrm{CO}_{2}\right)$ response during incremental exercise test in 4 patients with chronic heart failure of progressive severity. Panel A, A 69-year-old male patient with dilated cardiomyopathy (left ejection fraction: 60\%; peak oxygen consumption $\left(\mathrm{VO}_{2}\right): 23.7 \mathrm{~mL} \cdot \mathrm{kg}^{-1} \cdot \mathrm{min}^{-1}$; $\mathrm{VE} / \mathrm{VCO}_{2}$ slope (rest-peak): 33.0). $\mathrm{P}_{\mathrm{ETCO}} \mathrm{CO}_{2}$ at rest was $29.0 \mathrm{mmHg}$ and change in $\mathrm{P}_{\mathrm{ET}} \mathrm{CO}_{2}$ from rest to the highest value attained during exercise $\left(\triangle \mathrm{P}_{\mathrm{ET}} \mathrm{CO}_{2}\right.$ rest-exercise) was $6.3 \mathrm{mmHg}$. Panel $B$, A 58-year-old male patient with ischemic heart failure (left ejection fraction: $42 \%$; peak $\mathrm{VO}_{2}: 19.0 \mathrm{~mL} \cdot \mathrm{kg}^{-1} \cdot \mathrm{min}^{-1}$; VE/VCO 2 slope (rest-peak): 40.5 ). $\mathrm{P}_{\mathrm{ET}} \mathrm{CO}_{2}$ at rest was $25.1 \mathrm{mmHg}$ and $\triangle \mathrm{P}_{\mathrm{ET}} \mathrm{CO}_{2}$ rest-exercise was $5.8 \mathrm{mmHg}$. Panel C, A 60-year-old female patient with ischemic heart failure (left ejection fraction: $38 \%$; peak $\mathrm{VO}_{2}$ : $13.1 \mathrm{~mL} \cdot \mathrm{kg}^{-1} \cdot \mathrm{min}^{-1}$; $\mathrm{VE} / \mathrm{VCO}_{2}$ slope (rest-peak): 47.1 ). $\mathrm{P}_{\mathrm{ET}} \mathrm{CO}_{2}$ at rest was $23.0 \mathrm{mmHg}$ and $\Delta \mathrm{P}_{\mathrm{ET}} \mathrm{CO}_{2}$ rest-exercise was $5.0 \mathrm{mmHg}$. Panel $\mathrm{D}, \mathrm{A} 79$-year-old female patient with Chagas cardiomyopathy (left ejection fraction: $29 \%$; peak $\mathrm{VO}_{2}$ : $10.4 \mathrm{~mL} \cdot \mathrm{kg}^{-1} \cdot \mathrm{min}^{-1} ; \mathrm{VE} / \mathrm{NCO}_{2}$ slope (rest-peak): 63.8). $\mathrm{P}_{\mathrm{ET}} \mathrm{CO}_{2}$ at rest was $24.9 \mathrm{mmHg}$ and $\Delta \mathrm{P}_{\mathrm{ET}} \mathrm{CO}_{2}$ rest-exercise failed to increase.

3) abnormal ergoreflex and chemoreflex control leading to a high ventilatory drive $(8,9,42-47)$.

Previous investigations $(44,45,48)$ found ventilationperfusion inequalities during exercise in CHF patients. In fact, this finding suggests pathologically high ventilationperfusion mismatching (i.e., reduced or absent perfusion in well ventilated lung). It should also be highlighted that Wasserman et al. (44) also suggested that structural changes in the lungs and pulmonary vasoconstriction are responsible for the excessive ventilation observed in $\mathrm{CHF}$ patients. Additionally, the occurrence of alterations in breathing pattern is associated with a lower rate of increase in VT and higher respiratory rate (e.g., an increase in VD/VT). In this context, patients with heart failure have been shown to develop lung restrictive defects resulting in a shift to low operational lung volumes and a tachypneic breathing pattern (45).

There is also evidence from previous studies (49-51) that $\mathrm{CHF}$ patients may demonstrate impaired skeletal muscle metabolism intrinsic to reduced mitochondrial oxidative capacity. Specifically, mitochondrial enzymes (citrate synthase, and succinic dehydrogenase) and enzymes involved in $\beta$-oxidation have been shown to be decreased
$(51,52)$. Notably, a previous study showed a close relationship between a decrease in cytochrome oxidase activity and reduction in peak $\mathrm{VO}_{2}$ in heart failure patients (51). Additionally, skeletal muscle characteristics have important roles on substrate and oxygen utilization during physical exercise. Patients with heart failure have shown skeletal muscle abnormalities related to decreases in oxidative type I fibers and increases in glycolytic type Ilb fibers $(49,52)$. Together, these alterations indicate a shift from aerobic to anaerobic metabolism, which results in early occurrence of metabolic acidosis and exercise intolerance.

Furthermore, the blunted cardiac output response during exercise observed in CHF patients is associated with a decrease in convective $\mathrm{O}_{2}$ transport to working muscle, thereby increasing anaerobic glycolysis (9). Thus, enhanced lactic acidosis at lower work rates leads to an increase in $\mathrm{H}^{+}$stimulus, augmenting ventilation drive and fatigue in these patients.

It should also be noted that afferent feedback linked to receptors in locomotor muscle (ergoreflex activation) originating from groups III and IV (myelinated and unmyelinated, respectively) contributes to altered ventilatory control during exercise in heart failure patients $(42,43)$. More specifically,

\begin{tabular}{|l|c|c|c|c|}
\hline \multicolumn{1}{|c|}{ Ventilatory Class } & I & II & III & IV \\
\hline $\mathrm{VE} N \mathrm{NCO}_{2}$ Slope & $<30.0$ & $30.0-35.9$ & $36.0-44.9$ & $\geq 45.0$ \\
$\mathrm{PETCO}_{2}$ at rest $(\mathrm{mmHg})$ & $\geq 33.0$ & $\geq 33.0$ & $<33.0$ & $<33.0$ \\
$\mathrm{P}_{\mathrm{ETCO}}$ during exercise $(\mathrm{mmHg})$ & $3-8$ (increase) & $3-8$ (increase) & $<3$ (increase) & $<3$ (increase) \\
\hline
\end{tabular}

Figure 3. Four progressively worse ventilatory classes. $\mathrm{P}_{\mathrm{ET}} \mathrm{CO}_{2}$ : end-tidal $\mathrm{CO}_{2}$ pressure; $\mathrm{VE} / \mathrm{VCO}_{2}$ : ventilation to carbon dioxide production relationship. Adapted from reference (32). 
afferent neural feedback from skeletal muscle is an established regulator of cardiovascular and respiratory control during exercise in both animal and healthy humans (43). For instance, ergoreflex activation during exercise is stimulated by mechanical distortion of the receptive field (group III) and by products of metabolism (group IV). An interesting study carried out by Olson et al. (43) found that inhibiting afferent feedback from locomotor muscle via intrathecal opioid administration significantly reduced ventilatory response during exercise in $\mathrm{CHF}$ patients when compared to placebo $\left(\mathrm{VE} / \mathrm{VCO}_{2}\right.$ ratio $=33.8 \pm 1.1$ vs $28.1 \pm 0.7$ units, respectively).

Further pathophysiological evidence for increased ventilatory inefficiency response to exercise in heart failure can be found in impaired chemoreflex control $(9,46)$. Chemoreflexes are the dominant control mechanisms regulating ventilatory responses to changes in arterial oxygen and $\mathrm{CO}_{2}$ content. Narkiewicz et al. (46) showed that CHF patients are characterized by greater activation of ventilatory responses to central chemoreceptor activation by hypercapnia $\left(\mathrm{P}_{\mathrm{ET}} \mathrm{CO}_{2}=50 \mathrm{mmHg}\right)$ than normal subjects. Moreover, Giannoni et al. (47) demonstrated an enhanced chemosensitivity to hypoxia in systolic heart failure patients. Noteworthy, in the same investigation the authors observed that an increase in both hypoxic and hypercapnic chemosensitivity is related to autonomic imbalance, neurohormonal activation and ventilatory inefficiency in CHF patients.

This evidence, taken together with the aforementioned findings, suggests that both peripheral and central mechanisms may be associated with reduced ventilatory efficiency in heart failure patients (Figure 4).

Regarding CAD patients without CHF, it seems unlikely that these individuals have alterations in breathing pattern during exercise. However, the ventilatory inefficiency in CAD patients may be related with reduced aerobic capacity (6) and high ventilation-perfusion mismatching (41). In this context, Eto et al. (41) showed an association between impaired cardiac inotropic function and ventilatory inefficiency in patients after acute myocardial infarction.

Moreover, a previous study showed that alterations in chemoreflex control, possibly through excessive sympathetic tone, may also be associated (50). Specifically, the enhanced central hypercapnic chemosensitivity increases sympathetic outflow and therefore an increase in ventilatory response is observed (45). In this context, Tomita et al. (53) demonstrated that CAD patients with ventilatory inefficiency $\left(\mathrm{VE} / \mathrm{VCO}_{2}\right.$ slope $\left.=35 \pm 5\right)$ had increased $\mathrm{CO}_{2}$ chemosensitivity. Further investigations are necessary to confirm these issues.

\section{Effect of exercise training on ventilatory inefficiency in heart disease}

Substantial evidence $(6,7,10,13,14,41,48,50,53)$ supports the benefits of exercise training-based cardiac rehabilitation in heart disease. In fact, previous investigation have shown that when patients with heart disease are submitted to dynamic exercise training programs, aerobic capacity can improve by up to $25 \%$ (54). Additionally, a growing body of research $(6,7,10,13,14,41,48,53)$ shows improved ventilatory efficiency in heart patients after exercise training. Furthermore, a $\mathrm{VE} / \mathrm{VCO}_{2}$ slope reduction of between 6 and $23 \%$ has been observed in chronic heart failure patients after exercise training programs. In this respect, Gademan et al. (14) showed improvement in ventilatory efficiency $\left(\mathrm{VE} / \mathrm{VCO}_{2}\right.$ slope, pre- $=35.8 \pm 3.9$ vs post-training $=31.0 \pm 6.1$ units, $\Delta$ change $=-14 \%$ ) in $\mathrm{CHF}$ patients after exercise training. Similarly, Meyer et al. (55) observed a $14.6 \%$ decrease in $\mathrm{VE} / \mathrm{VCO}_{2}$ slope after shortterm exercise training ( 3 weeks) in patients with severe CHF.

In CAD patients, Tomita et al. (53) found a decrease in $\mathrm{VE} / \mathrm{VCO}_{2}$ slope after aerobic exercise training. Furthermore, Rocco et al. (6) evaluated the effects of continuous and interval exercise training on $\mathrm{P}_{\mathrm{ET}} \mathrm{CO}_{2}$ response during

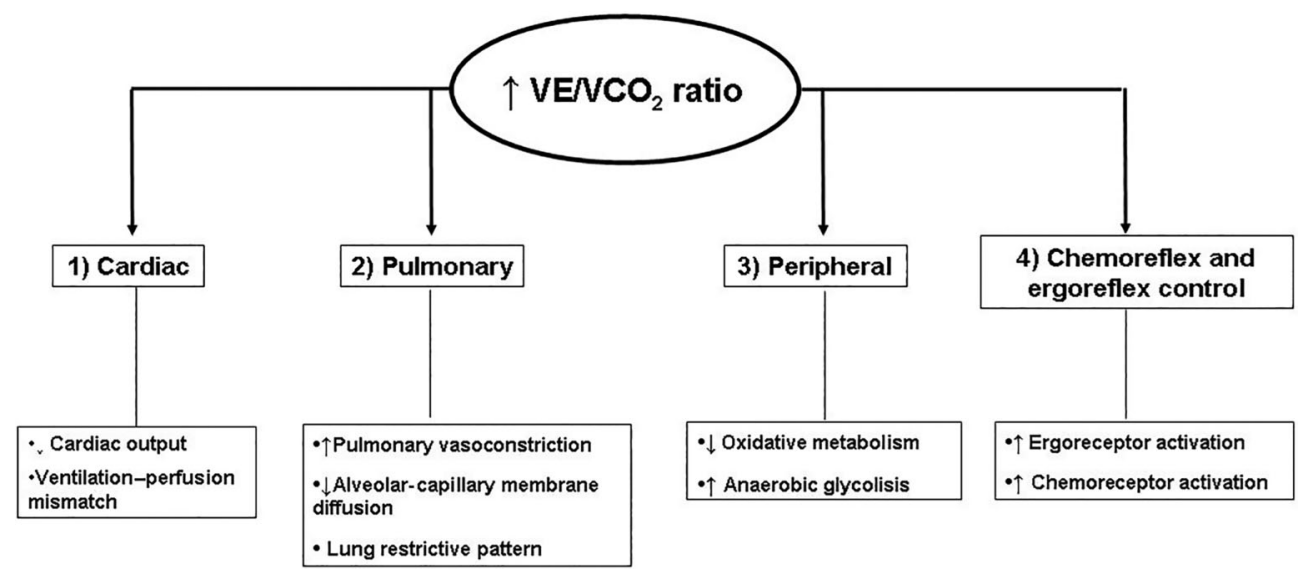

Figure 4. Potential mechanisms suggested for reduced ventilatory efficiency (increased ventilation to carbon dioxide production relationship $\left(\mathrm{VE} / \mathrm{VCO}_{2}\right)$ in cardiac disease. 
graded exercise tests. Interestingly, after a 12-week exercise training program, CAD patients submitted to both exercise training methods showed a similar response in decrease ventilatory inefficiency (6) (Figure 5)

In addition, Prado et al. (7) investigated whether aerobic fitness status was associated with greater improvements in ventilatory efficiency in CAD patients after aerobic exercise training. More specifically, 123 patients with CAD were divided into 3 groups: group 1 $\left(\mathrm{n}=34\right.$, peak $\left.\mathrm{VO}_{2}<17.5 \mathrm{~mL} \cdot \mathrm{kg}^{-1} \cdot \mathrm{min}^{-1}\right)$; group $2(\mathrm{n}=67$, peak $\mathrm{VO}_{2}>17.5$ and $<24.5 \mathrm{~mL} \cdot \mathrm{kg}^{-1} \cdot \mathrm{min}^{-1}$ ) and group 3 $\left(\mathrm{n}=22\right.$, peak $\left.\mathrm{VO}_{2}>22.5 \mathrm{~mL} \cdot \mathrm{kg}^{-1} \cdot \mathrm{min}^{-1}\right)$. After 12 weeks of an aerobic exercise training program, the CAD patients with lower initial aerobic fitness exhibited greater improvements in ventilatory efficiency than the other groups (Figure 6).

Concerning the physiological mechanisms responsible for increasing ventilatory efficiency after exercise training programs, these may be dependent on peripheral and central mechanisms. A determinant role of locomotor muscle abnormalities in limited exercise performance in heart failure is well documented $(9,42,43,49,50)$. Notably, aerobic exercise training not only improves peak $\mathrm{VO}_{2}$ but also promotes a number of significant changes in the exercising limbs, such as increased $\mathrm{O}_{2}$ uptake and arteriovenous $\mathrm{O}_{2}$ difference, as well as decreased lactate accumulation and ergoreflex activation (50). Supporting this notion, Van Laethem et al. (56) attributed improvements in muscle receptor reflexes and skeletal muscle metabolism after aerobic exercise training to more

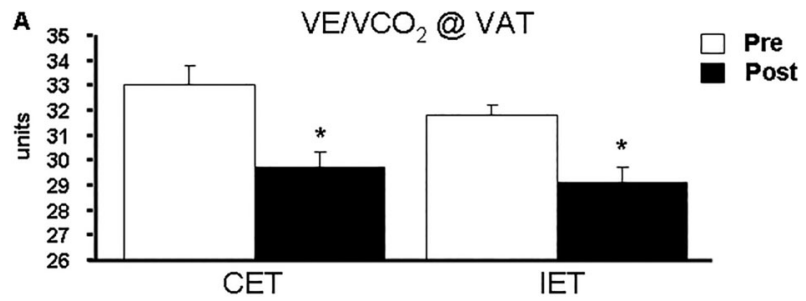

B

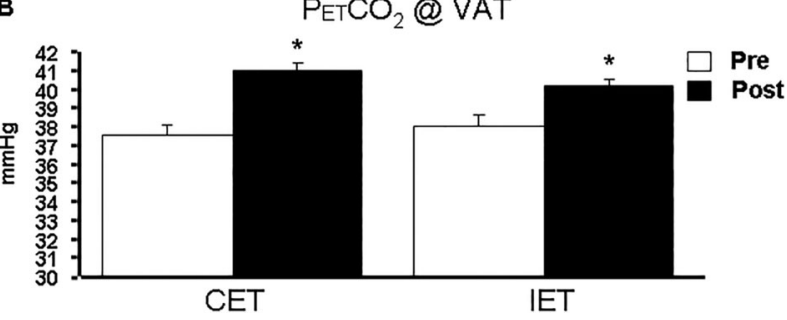

Figure 5. Effects of continuous exercise (CET) and interval exercise training (IET) on indices of ventilatory efficiency in coronary artery disease patients. Panel $A$, Ventilation to carbon dioxide production relationship $\left(\mathrm{VE} / \mathrm{VCO}_{2}\right)$ at ventilatory anaerobic threshold (VAT); Panel B, End-tidal $\mathrm{CO}_{2}$ pressure $\left(\mathrm{P}_{\mathrm{ET}} \mathrm{CO}_{2}\right)$ at VAT. Pre: pre-intervention; Post: post-intervention. ${ }^{*} \mathrm{P}<0.05$ vs pre-intervention. Adapted from reference (6). efficient ventilation during exercise in CHF patients. Moreover, a previous study (42) demonstrated that, after exercise training, an improvement in ergoreflex control was associated with a $46.9 \%$ decrease in ventilatory response during exercise in $\mathrm{CHF}$ patients. Furthermore, Adamopoulos et al. (50), studying patients with heart failure after 8 weeks of exercise training, found lower phosphocreatine depletion and a smaller increase in adenosine diphosphate at matched submaximal workloads. These findings suggest an improvement in oxidative metabolism related to an increase in mitochondrial content or activity.

With respect to central mechanisms, previous studies $(10,57)$ have demonstrated the beneficial effects of exercise training in improving cardiac output among CHF patients. Coats et al. (10) for example, in 17 patients with moderate to severe $\mathrm{CHF}$ that underwent 8 weeks of exercise training, observed an increase in submaximal cardiac output (pre- $=5.9$ vs post-training $=6.7 \mathrm{~L} / \mathrm{min}$, respectively) and peak cardiac output (pre- $=6.3$ vs posttraining $=7.1 \mathrm{~L} / \mathrm{min}$, respectively). Based on these findings, it seems reasonable to speculate that an increase in cardiac output after exercise training programs can improve convective $\mathrm{O}_{2}$ transport to the working locomotor muscle, thus reducing both metabolic disturbance and ergoreflex activation during exercise in CHF patients. In fact, limited cardiac output increase during exercise and oxidative metabolism impairment in working locomotor muscle are associated with the development of early lactic acidosis during exercise in heart failure patients.

Importantly, Guazzi et al. (48) showed that exercise training significantly improved alveolar-capillary membrane capacity $\left(D_{M}\right)$ in $C H F\left(D_{M}\right.$, pre-=31.4 \pm 3.2 vs post-training $=36.1 \pm 3.8 \mathrm{~mL} \cdot \mathrm{min}^{-1} \cdot \mathrm{mmHg}^{-1}$, respectively). According to the authors, this finding can be explained by higher cardiac output and better diffusion-perfusion matching (i.e., improved ventilation/perfusion ratio). This result shows that impairment in lung diffusion among CHF patients is involved in ventilatory inefficiency and that there is a link between changes in lung function and improvement in exercise capacity with exercise training.

Notably, previous studies support the notion that chemoreflex abnormalities play a role in ventilatory inefficiency in heart failure $(46,47)$. In this context, CHF patients have enhanced chemoreflex sensitivity through augmented afferent input from the carotid body (47). Importantly, the beneficial effects of exercise training on peripheral chemoreflex sensitivity in heart failure patients have also been documented (58). For instance, improvement in peripheral chemoreflex control was normalized after exercise training in a rabbit model of heart failure (58). These findings are associated to reversal of alterations in angiotensin II systems and nitric oxide expression in the carotid body [59]. With respect to central $\mathrm{CO}_{2}$ chemosensitivity, to date, little is known about the effects of exercise training on hypercapnic chemoreflex sensitivity 


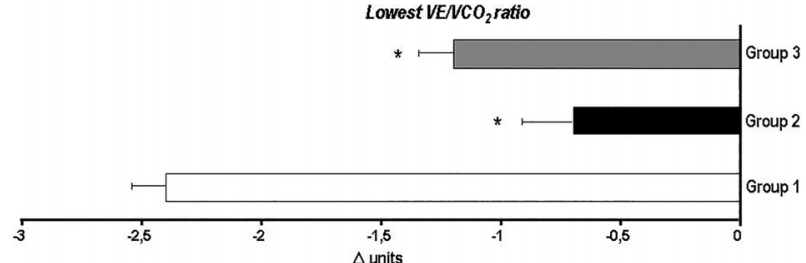

Figure 6. Absolute changes in ventilatory efficiency among coronary artery disease patients after aerobic exercise training program. Group $1\left(\mathrm{n}=34\right.$, peak $\mathrm{VO}_{2}<17.5 \mathrm{~mL} \cdot \mathrm{kg}^{-1} \cdot \mathrm{min}^{-1}$; lowest $\mathrm{VE} / \mathrm{VCO}_{2}$ ratio 33.5); group $2\left(\mathrm{n}=67\right.$, peak $\mathrm{VO}_{2}>17.5$ and $<24.5 \mathrm{~mL} \cdot \mathrm{kg}^{-1} \cdot \mathrm{min}^{-1}$; lowest $\mathrm{VE} / \mathrm{VCO}_{2}$ ratio 29.7$)$ and group 3 $\left(\mathrm{n}=22\right.$, peak $\mathrm{VO}_{2}>24.5 \mathrm{~mL} \cdot \mathrm{kg}^{-1} \cdot \mathrm{min}^{-1}$; lowest $\mathrm{VE} / \mathrm{VCO}_{2}$ ratio 29.0). Note that group 1 showed a greater decrease in the lowest $\mathrm{VE} / \mathrm{VCO}_{2}$ ratio compared to the other two groups. $\mathrm{VE} / \mathrm{VCO}_{2}$ : ventilation to carbon dioxide production relationship; $\mathrm{VO}_{2}$ : oxygen consumption. ${ }^{*} \mathrm{P}<0.05$ vs group 1 (one-way ANOVA). Adapted from reference (7).

in CHF patients. However, concerning CAD patients, a previous study (53) showed that reduced $\mathrm{VE} / \mathrm{VCO}_{2}$ slope after exercise training was correlated with attenuation in $\mathrm{CO}_{2}$ chemosensitivity. Interestingly, the suppression of hypercapnic chemoreflex response was associated with improvement in the sensation of dyspnea during exercise in CAD patients. Additionally, other investigations suggest that both oxidative metabolism and ventilation/perfusion matching are factors contributing to reduced ventilatory inefficiency after aerobic exercise training in CAD patients $(6,7,53)$ (Figure 7$)$

For example, Rocco et al. (6) showed a positive association between $\mathrm{P}_{\mathrm{ET}} \mathrm{CO}_{2}$ and $\mathrm{VO}_{2}$ at VAT, suggesting that increases in $\mathrm{P}_{\mathrm{ET}} \mathrm{CO}_{2}$ after aerobic exercise training were related to improvements in aerobic metabolism. In the same study, the authors also observed that higher $\mathrm{P}_{\mathrm{ET}} \mathrm{CO}_{2}$ values after exercise training were associated with lower VD/NT at VAT. Furthermore, Prado et al. (7) demonstrated after 12 weeks of aerobic exercise training, that increased peak $\mathrm{O}_{2}$ pulse (pre- $10.1 \pm 0.6$ vs posttraining $16.1 \pm 3.1 \mathrm{~mL} / \mathrm{bpm}$, respectively) was associated with a decrease in the lowest $\mathrm{VE} / \mathrm{VCO}_{2}$ ratio among CAD patients with lower aerobic fitness. Overall, the aforementioned findings suggest an improvement in ventilation/ perfusion matching during exercise.

\section{Conclusion}

Exercise limitation is an important manifestation accompanied by ventilatory inefficiency in patients with cardiorespiratory disease. Analysis of ventilatory efficiency during
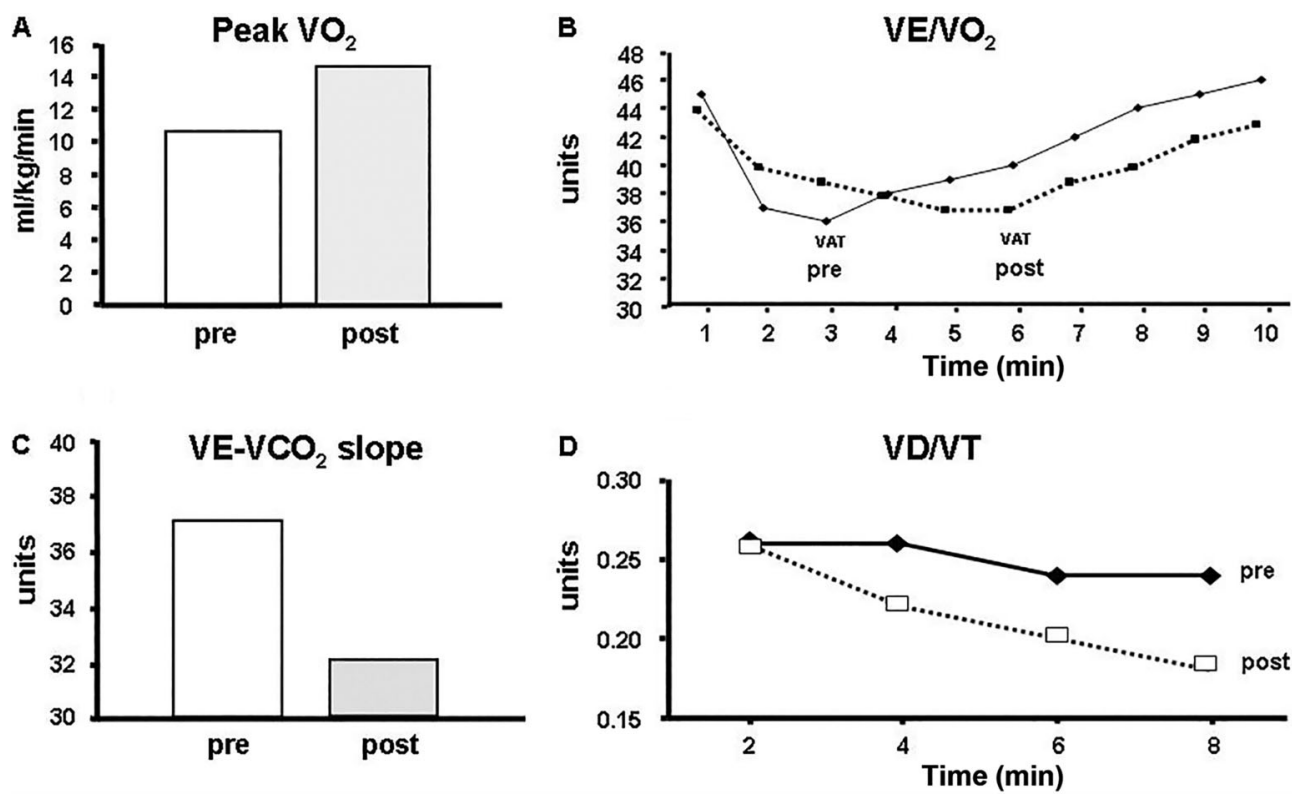

Figure 7. Effect of a 12-week aerobic exercise training program in an 82-year-old female patient with coronary artery disease. Panel $A$, peak oxygen consumption $\left(\mathrm{VO}_{2}\right)$; panel $B, \mathrm{VE} / \mathrm{VO}_{2}$, ventilatory equivalent for oxygen; panel $C$, ventilation to carbon dioxide production relationship $\left(\mathrm{VE}-\mathrm{VCO}_{2}\right)$ slope (rest-peak); panel $D$, dead space to tidal volume ratio (VD/VT). Note that after aerobic exercise training the patient showed improvement in both aerobic fitness and ventilatory efficiency (panels $A$ and $C$, respectively). The patient demonstrated a marked shift to the right of the VAT suggesting improvement in aerobic efficiency (panel $B$ ). In addition, the patient demonstrated a sharper reduction in VD/VT showing improvement in gas exchange efficiency (panel $D$ ). pre: pre-intervention; post: post-intervention; VAT: ventilatory anaerobic threshold; VD/VT: estimate physiological dead space to tidal volume ratio. 
exercise has proven useful for assessing the presence and severity of heart disease even in patients without apparent exercise limitation. The bulk of evidence has shown that improvements in ventilatory efficiency among heart patients after exercise training may be dependent on peripheral and central mechanisms. Taken together, these findings suggest that exercise programs have clinically significant effects because the low ventilatory efficiency observed in patients with heart diseases constitutes an important predictor of cardiovascular mortality.

\section{References}

1. Fletcher GF, Ades PA, Kligfield P, Arena R, Balady GJ, Bittner VA, et al. Exercise standards for testing and training: a scientific statement from the American Heart Association. Circulation 2013; 128: 873-934. doi: 10.1161/CIR.0b013e3182 $9 b 5 b 44$.

2. Wasserman K. Cardiopulmonary exercise testing and cardiovascular health. Armonk: Futura; 2002.

3. Arena R, Myers J, Guazzi M. The clinical and research applications of aerobic capacity and ventilatory efficiency in heart failure: an evidence-based review. Heart Fail Rev 2008; 13: 245-269. doi: 10.1007/s10741-007-9067-5.

4. Gitt AK, Wasserman K, Kilkowski C, Kleemann T, Kilkowski A, Bangert $\mathrm{M}$, et al. Exercise anaerobic threshold and ventilatory efficiency identify heart failure patients for high risk of early death. Circulation 2002; 106: 3079-3084. doi: 10.1161/ 01.CIR.0000041428.99427.06.

5. Arena R, Myers J, Abella J, Peberdy MA, Bensimhon D, Chase $P$, et al. Development of a ventilatory classification system in patients with heart failure. Circulation 2007; 115: 2410-2417. doi: 10.1161/CIRCULATIONAHA.107.686576.

6. Rocco EA, Prado DM, Silva AG, Lazzari JM, Bortz PC, Rocco DF, et al. Effect of continuous and interval exercise training on the $\mathrm{PETCO}_{2}$ response during a graded exercise test in patients with coronary artery disease. Clinics 2012; 67: 623-628. doi: 10.6061/clinics/2012(06)13.

7. Prado DM, Rocco EA, Silva AG, Silva PF, Lazzari JM, Assumpcao GL, et al. The influence of aerobic fitness status on ventilatory efficiency in patients with coronary artery disease. Clinics 2015; 70: 46-51. doi: 10.6061/clinics/2015(01)09.

8. Woods PR, Olson TP, Frantz RP, Johnson BD. Causes of breathing inefficiency during exercise in heart failure. $J$ Card Fail 2010; 16: 835-842. doi: 10.1016/j.cardfail.2010.05.003.

9. Guazzi M. Abnormalities in cardiopulmonary exercise testing ventilatory parameters in heart failure: pathophysiology and clinical usefulness. Curr Heart Fail Rep 2014; 11: 80-87. doi: 10.1007/s11897-013-0183-3.

10. Coats AJ, Adamopoulos S, Radaelli A, McCance A, Meyer TE, Bernardi $\mathrm{L}$, et al. Controlled trial of physical training in chronic heart failure. Exercise performance, hemodynamics, ventilation, and autonomic function. Circulation 1992; 85: 2119-2131. doi: 10.1161/01.CIR.85.6.2119.

11. Prado DM, Benatti FB, de Sa-Pinto AL, Hayashi AP, Gualano B, Pereira RM, et al. Exercise training in childhood-onset systemic lupus erythematosus: a controlled randomized trial. Arthritis Res Ther 2013; 15: R46. doi: 10.1186/ar4205.

12. Puente-Maestu L, Sanz ML, Sanz P, Ruiz de Ona JM, Rodriguez-Hermosa JL, Whipp BJ. Effects of two types of training on pulmonary and cardiac responses to moderate exercise in patients with COPD. Eur Respir J 2000; 15: 1026-1032. doi: 10.1034/j.1399-3003.2000.01509.x.

13. Defoor J, Schepers D, Reybrouck T, Fagard R, Vanhees L. Oxygen uptake efficiency slope in coronary artery disease: clinical use and response to training. Int J Sports Med 2006; 27: 730-737. doi: 10.1055/s-2005-872910.

14. Gademan MG, Swenne CA, Verwey HF, van de Vooren $H$, Haest JC, van Exel $\mathrm{HJ}$, et al. Exercise training increases oxygen uptake efficiency slope in chronic heart failure. Eur $\mathrm{J}$ Cardiovasc Prev Rehabil 2008; 15: 140-144. doi: 10.1097/ HJR.0b013e3282ef19986.

15. Whipp BJ, Ward SA. Determinants and control of breathing during muscular exercise. Br J Sports Med 1998; 32: 199211. doi: 10.1136/bjsm.32.3.199.

16. Wasserman $\mathrm{K}$, Whipp BJ. Exercise physiology in health and disease. Am Rev Respir Dis 1975; 112: 219-249.

17. Shea SA, Andres LP, Shannon DC, Banzett RB. Ventilatory responses to exercise in humans lacking ventilatory chemosensitivity. J Physiol 1993; 468: 623-640. doi: 10.1113/jphysiol.1993.sp019792

18. Wasserman K, Hansen JE, Sue DY, Whipp BJ. Principles of exercise testing and interpretation. Philadelphia: Lea \& Febiger; 1987.

19. Jones NL. Normal values for pulmonary gas exchange during exercise. Am Rev Respir Dis 1984; 129: S44-S46. doi: 10.1164/arrd.1984.129.2P2.S44.

20. Fink GR, Adams L, Watson JD, Innes JA, Wuyam B, Kobayashi I, et al. Hyperpnoea during and immediately after exercise in man: evidence of motor cortical involvement. J Physiol 1995; 489 (Part 3): 663-675. doi: 10.1113/ jphysiol.1995.sp021081.

21. Dempsey JA. New perspectives concerning feedback influences on cardiorespiratory control during rhythmic exercise and on exercise performance. J Physiol 2012; 590: 4129-4144. doi: 10.1113/jphysiol.2012.233908.

22. Amann M, Blain GM, Proctor LT, Sebranek JJ, Pegelow DF, Dempsey JA. Implications of group III and IV muscle afferents for high-intensity endurance exercise performance in humans. J Physiol 2011; 589: 5299-5309. doi: 10.1113/ jphysiol.2011.213769.

23. Amann M, Blain GM, Proctor LT, Sebranek JJ, Pegelow DF, Dempsey JA. Group III and IV muscle afferents contribute to ventilatory and cardiovascular response to rhythmic exercise in humans. J Appl Physiol 2010; 109: 966-976. doi: 10.1152/japplphysiol.00462.2010.

24. Sun XG, Hansen JE, Oudiz RJ, Wasserman K. Exercise pathophysiology in patients with primary pulmonary hypertension. Circulation 2001; 104: 429-435. doi: 10.1161/hc2901. 093198.

25. Wasserman $\mathrm{K}$, Zhang $\mathrm{YY}$, Riley MS. Ventilation during exercise in chronic heart failure. Basic Res Cardiol 1996; 91 (Suppl 1): 1-11. doi: 10.1007/BF00810518.

26. Metra M, Dei CL, Panina G, Visioli O. Exercise hyperventilation chronic congestive heart failure, and its relation to functional capacity and hemodynamics. Am J Cardiol 1992; 70: 622-628. doi: 10.1016/0002-9149(92)90202-A. 
27. Hansen JE, Wasserman K. Pathophysiology of activity limitation in patients with interstitial lung disease. Chest 1996; 109: 1566-1576. doi: 10.1378/chest.109.6.1566.

28. Torchio R, Guglielmo M, Giardino R, Ardissone F, Ciacco C, Gulotta $C$, et al. Exercise ventilatory inefficiency and mortality in patients with chronic obstructive pulmonary disease undergoing surgery for non-small-cell lung cancer. Eur J Cardiothorac Surg 2010; 38: 14-19. doi: 10.1016/ j.ejcts.2010.01.032.

29. Arena R, Myers J, Aslam SS, Varughese EB, Peberdy MA. Technical considerations related to the minute ventilation/ carbon dioxide output slope in patients with heart failure. Chest 2003; 124: 720-727. doi: 10.1378/chest.124.2.720.

30. Arena R, MacCarter D, Olson TP, Lalande S, Ceridon ML, Olson LJ, et al. Ventilatory expired gas at constant-rate lowintensity exercise predicts adverse events and is related to neurohormonal markers in patients with heart failure. $J$ Card Fail 2009; 15: 482-488. doi: 10.1016/j.cardfail.2008.12.015.

31. Sun XG, Hansen JE, Garatachea N, Storer TW, Wasserman K. Ventilatory efficiency during exercise in healthy subjects. $\mathrm{Am} \mathrm{J}$ Respir Crit Care Med 2002; 166: 1443-1448. doi: 10.1164/ rccm.2202033.

32. Schwaiblmair M, Faul C, von Scheidt W, Berghaus TM. Ventilatory efficiency testing as prognostic value in patients with pulmonary hypertension. BMC Pulm Med 2012; 12: 23. doi: 10.1186/1471-2466-12-23.

33. Guazzi M, Adams V, Conraads V, Halle M, Mezzani A, Vanhees L, et al. EACPR/AHA Joint Scientific Statement. Clinical recommendations for cardiopulmonary exercise testing data assessment in specific patient populations. Eur Heart J 2012; 33: 2917-2927. doi: 10.1093/eurheartj/ ehs221.

34. Hansen JE, Ulubay G, Chow BF, Sun XG, Wasserman K. Mixed-expired and end-tidal $\mathrm{CO}_{2}$ distinguish between ventilation and perfusion defects during exercise testing in patients with lung and heart diseases. Chest 2007; 132: 977-983. doi: 10.1378/chest.07-0619.

35. Tanabe $Y$, Hosaka $Y$, Ito M, Ito E, Suzuki K. Significance of end-tidal $\mathrm{P}(\mathrm{CO}(2))$ response to exercise and its relation to functional capacity in patients with chronic heart failure. Chest 2001; 119: 811-817. doi: 10.1378/chest.119.3.811.

36. Yasunobu Y, Oudiz RJ, Sun XG, Hansen JE, Wasserman K. End-tidal $\mathrm{PCO}_{2}$ abnormality and exercise limitation in patients with primary pulmonary hypertension. Chest 2005; 127: 1637-1646. doi: 10.1378/chest.127.5.1637.

37. Shen $\mathrm{Y}$, Zhang $\mathrm{X}$, Ma W, Song $\mathrm{H}$, Gong Z, Wang Q, et al. VE/VCO slope and its prognostic value in patients with chronic heart failure. Exp Ther Med 2015; 9: 1407-1412.

38. Chua TP, Ponikowski P, Harrington D, Anker SD, WebbPeploe K, Clark AL, et al. Clinical correlates and prognostic significance of the ventilatory response to exercise in chronic heart failure. J Am Coll Cardiol 1997; 29: 15851590. doi: 10.1016/S0735-1097(97)00078-8.

39. Kleber FX, Vietzke G, Wernecke KD, Bauer U, Opitz C, Wensel $R$, et al. Impairment of ventilatory efficiency in heart failure: prognostic impact. Circulation 2000; 101: 28032809. doi: 10.1161/01.CIR.101.24.2803.

40. Ponikowski P, Francis DP, Piepoli MF, Davies LC, Chua TP, Davos $\mathrm{CH}$, et al. Enhanced ventilatory response to exercise in patients with chronic heart failure and preserved exercise tolerance: marker of abnormal cardiorespiratory reflex control and predictor of poor prognosis. Circulation 2001; 103: 967-972. doi: 10.1161/01.CIR.103.7.967.

41. Eto $Y$, Koike A, Matsumoto A, Momomura S, Tajima A, Aizawa $\mathrm{T}$, et al. Early aerobic training increases end-tidal $\mathrm{CO}_{2}$ pressure during exercise in patients after acute myocardial infarction. Circ J 2004; 68: 778-783. doi: 10.1253/circj.68.778.

42. Piepoli $M$, Clark AL, Volterrani $M$, Adamopoulos S, Sleight $P$, Coats AJ. Contribution of muscle afferents to the hemodynamic, autonomic, and ventilatory responses to exercise in patients with chronic heart failure: effects of physical training. Circulation 1996; 93: 940-952. doi: 10.1161/01.CIR.93. 5.940 .

43. Olson TP, Joyner MJ, Eisenach JH, Curry TB, Johnson BD. Influence of locomotor muscle afferent inhibition on the ventilatory response to exercise in heart failure. Exp Physiol 2014; 99: 414-426. doi: 10.1113/expphysiol.2013.075937.

44. Wasserman K, Zhang YY, Gitt A, Belardinelli R, Koike A, Lubarsky $L$, et al. Lung function and exercise gas exchange in chronic heart failure. Circulation 1997; 96: 2221-2227. doi: 10.1161/01.CIR.96.7.2221.

45. Apostolo A, Giusti G, Gargiulo P, Bussoti M, Agostoni P. Lungs in heart failure. Pulm Med 2013; 99: 414-426.

46. Narkiewicz K, Pesek CA, van de Borne PJ, Kato M, Somers VK. Enhanced sympathetic and ventilatory responses to central chemoreflex activation in heart failure. Circulation 1999; 100: 262-267. doi: 10.1161/01.CIR.100.3.262.

47. Giannoni A, Emdin M, Bramanti F, ludice G, Francis DP, Barsotti $A$, et al. Combined increased chemosensitivity to hypoxia and hypercapnia as a prognosticator in heart failure. J Am Coll Cardiol 2009; 53: 1975-1980. doi: 10.1016/ j.jacc.2009.02.030.

48. Guazzi M, Reina G, Tumminello G, Guazzi MD. Improvement of alveolar-capillary membrane diffusing capacity with exercise training in chronic heart failure. J Appl Physiol 2004; 97: 1866-1873. doi: 10.1152/japplphysiol.00365.2004.

49. Okita $\mathrm{K}$, Kinugawa $\mathrm{S}$, Tsutsui $\mathrm{H}$. Exercise intolerance in chronic heart failure - skeletal muscle dysfunction and potential therapies. Circ J 2013; 77: 293-300. doi: 10.1253/ circj.CJ-12-1235.

50. Adamopoulos S, Coats AJ, Brunotte F, Arnolda L, Meyer T, Thompson $\mathrm{CH}$, et al. Physical training improves skeletal muscle metabolism in patients with chronic heart failure. J Am Coll Cardiol 1993; 21: 1101-1106. doi: 10.1016/07351097(93)90231-O

51. Drexler $H$, Riede $U$, Munzel $T$, Konig $H$, Funke $E$, Just $H$. Alterations of skeletal muscle in chronic heart failure. Circulation 1992; 85: 1751-1759. doi: 10.1161/01.CIR. 85.5.1751.

52. Sullivan MJ, Green HJ, Cobb FR. Skeletal muscle biochemistry and histology in ambulatory patients with long-term heart failure. Circulation 1990; 81: 518-527. doi: 10.1161/ 01.CIR.81.2.518.

53. Tomita T, Takaki H, Hara Y, Sakamaki F, Satoh T, Takagi S, et al. Attenuation of hypercapnic carbon dioxide chemosensitivity after postinfarction exercise training: possible contribution to the improvement in exercise hyperventilation. Heart 2003; 89: 404-410. doi: 10.1136/heart.89.4.404. 
54. Goebbels U, Myers J, Dziekan G, Muller P, Kuhn M, Ratte $R$, et al. A randomized comparison of exercise training in patients with normal vs reduced ventricular function. Chest 1998; 113: 1387-1393. doi: 10.1378/chest.113.5. 1387.

55. Meyer K, Schwaibold M, Westbrook S, Beneke R, Hajric R, Gornandt $L$, et al. Effects of short-term exercise training and activity restriction on functional capacity in patients with severe chronic congestive heart failure. Am J Cardiol 1996; 78: 1017-1022. doi: 10.1016/S0002-9149(96)00527-9.

56. Van Laethem C, Van De Veire N, De Backer G, Bihija S, Seghers $T$, Cambier D, et al. Response of the oxygen uptake efficiency slope to exercise training in patients with chronic heart failure. Eur J Heart Fail 2007; 9: 625-629. doi: 10.1016/j.ejheart.2007.01.007.

57. Hambrecht R, Gielen S, Linke A, Fiehn E, Yu J, Walther C, et al. Effects of exercise training on left ventricular function and peripheral resistance in patients with chronic heart failure: A randomized trial. JAMA 2000; 283: 3095-3101. doi: 10.1001/jama.283.23.3095.

58. Li YL, Ding Y, Agnew C, Schultz HD. Exercise training improves peripheral chemoreflex function in heart failure rabbits. J Appl Physiol 2008; 105: 782-790. doi: 10.1152/ japplphysiol.90533.2008. 